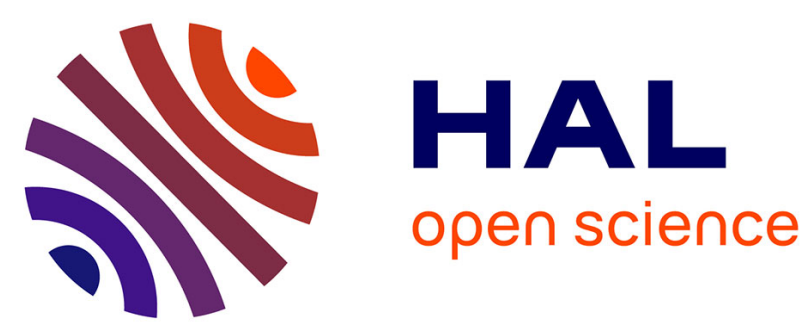

\title{
Twenty-First-Century Compatible CO2 Emissions and Airborne Fraction Simulated by CMIP5 Earth System Models under Four Representative Concentration Pathways
}

Chris Jones, Eddy Robertson, Vivek Arora, Pierre Friedlingstein, Elena Shevliakova, Laurent Bopp, Victor Brovkin, Tomohiro Hajima, Etsushi Kato, Michio Kawamiya, et al.

\section{- To cite this version:}

Chris Jones, Eddy Robertson, Vivek Arora, Pierre Friedlingstein, Elena Shevliakova, et al.. TwentyFirst-Century Compatible CO2 Emissions and Airborne Fraction Simulated by CMIP5 Earth System Models under Four Representative Concentration Pathways. Journal of Climate, 2013, 26 (13), pp.4398-4413. 10.1175/JCLI-D-12-00554.1 . hal-03208206

\section{HAL Id: hal-03208206 https://hal.science/hal-03208206}

Submitted on 11 Jun 2021

HAL is a multi-disciplinary open access archive for the deposit and dissemination of scientific research documents, whether they are published or not. The documents may come from teaching and research institutions in France or abroad, or from public or private research centers.
L'archive ouverte pluridisciplinaire HAL, est destinée au dépôt et à la diffusion de documents scientifiques de niveau recherche, publiés ou non, émanant des établissements d'enseignement et de recherche français ou étrangers, des laboratoires publics ou privés. 


\section{ORE Open Research Exeter}

\section{TITLE}

Twenty-first-century compatible co 2 emissions and airborne fraction simulated by cmip5 earth system models under four representative concentration pathways

\section{AUTHORS}

Jones, C; Robertson, E; Arora, V; et al.

\section{JOURNAL}

Journal of Climate

\section{DEPOSITED IN ORE}

06 April 2016

This version available at

http://hdl.handle.net/10871/20987 


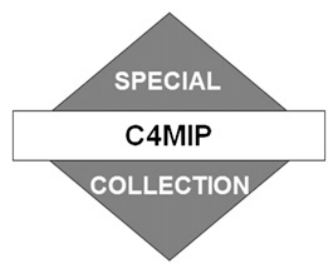

\title{
Twenty-First-Century Compatible $\mathrm{CO}_{2}$ Emissions and Airborne Fraction Simulated by CMIP5 Earth System Models under Four Representative Concentration Pathways
}

\author{
Chris Jones, ${ }^{\mathrm{a}}$ Eddy Robertson,,${ }^{\mathrm{a}}$ Vivek Arora, ${ }^{\mathrm{b}}$ Pierre Friedlingstein, ${ }^{\mathrm{c}}$ Elena Shevliakova, \\ LAUrent BopP, ${ }^{\mathrm{e}}$ Victor Brovkin, ${ }^{\mathrm{f}}$ TOMOHIRO HAJIMA, ${ }^{\mathrm{g}}$ ETSUSHI KATO, ${ }^{\mathrm{h}}$ MiCHIO KAWAMIYA, ${ }^{\mathrm{g}}$ \\ SPEnCER Liddicoat, ${ }^{a}$ KeIth Lindsay, ${ }^{i}$ Christian H. Reick, ${ }^{\mathrm{f}}$ CAROline RoElandt, ${ }^{\mathrm{j}}$ \\ JOACHIM SEGSCHNEIDER, ${ }^{f}$ AND JERRY TJIPUTRA ${ }^{j}$ \\ ${ }^{a}$ Met Office Hadley Centre, Exeter, United Kingdom \\ ${ }^{\mathrm{b}}$ Canadian Centre for Climate Modelling and Analysis, Environment Canada, University of Victoria, Victoria, \\ British Columbia, Canada \\ ${ }^{\mathrm{c}}$ College of Engineering, Mathematics and Physical Sciences, University of Exeter, Exeter, EX4 4QF, United Kingdom \\ ${ }^{\mathrm{d}}$ Department of Ecology and Evolutionary Biology, Princeton University, Princeton, New Jersey \\ ${ }^{\text {e }}$ LSCE, IPSL, CEA, UVSQ, CNRS, Gif-sur-Yvette, France \\ ${ }^{\mathrm{f}}$ Max Planck Institute for Meteorology, Hamburg, Germany \\ ${ }^{g}$ Research Institute for Global Change, Japan Agency for Marine-Earth Science and Technology, Yokohama, Japan \\ ${ }^{\text {h }}$ Center for Global Environmental Research, National Institute for Environmental Studies, Tsukuba, Japan \\ ${ }^{\mathrm{i}}$ Climate and Global Dynamics Division, National Center for Atmospheric Research, ${ }^{k}$ Boulder, Colorado \\ ${ }^{\mathrm{j}}$ Geophysical Institute, University of Bergen, Bergen, Norway
}

(Manuscript received 31 July 2012, in final form 3 January 2013)

\begin{abstract}
The carbon cycle is a crucial Earth system component affecting climate and atmospheric composition. The response of natural carbon uptake to $\mathrm{CO}_{2}$ and climate change will determine anthropogenic emissions compatible with a target $\mathrm{CO}_{2}$ pathway. For phase 5 of the Coupled Model Intercomparison Project (CMIP5), four future representative concentration pathways (RCPs) have been generated by integrated assessment models (IAMs) and used as scenarios by state-of-the-art climate models, enabling quantification of compatible carbon emissions for the four scenarios by complex, process-based models. Here, the authors present results from 15 such Earth system GCMs for future changes in land and ocean carbon storage and the implications for anthropogenic emissions. The results are consistent with the underlying scenarios but show substantial model spread. Uncertainty in land carbon uptake due to differences among models is comparable with the spread across scenarios. Model estimates of historical fossil-fuel emissions agree well with reconstructions, and future projections for representative concentration pathway 2.6 (RCP2.6) and RCP4.5 are consistent with the IAMs. For high-end scenarios (RCP6.0 and RCP8.5), GCMs simulate smaller compatible emissions than the IAMs, indicating a larger climate-carbon cycle feedback in the GCMs in these scenarios. For the RCP2.6 mitigation scenario, an average reduction of $50 \%$ in emissions by 2050 from 1990 levels is required but with very large model spread $(14 \%-96 \%)$. The models also disagree on both the requirement for sustained negative emissions to achieve the RCP2.6 $\mathrm{CO}_{2}$ concentration and the success of this scenario to restrict global warming below $2^{\circ} \mathrm{C}$. All models agree that the future airborne fraction depends strongly on the emissions profile with higher airborne fraction for higher emissions scenarios.
\end{abstract}

\footnotetext{
${ }^{\mathrm{k}}$ The National Center for Atmospheric Research is sponsored by the National Science Foundation.

Corresponding author address: Chris Jones, Met Office Hadley Centre, FitzRoy Road, Exeter EX1 3PB, United Kingdom.

E-mail: chris.d.jones@metoffice.gov.uk
}

\section{Introduction}

The global carbon cycle has long been known to be a crucial component of future climate change, closely linking anthropogenic $\mathrm{CO}_{2}$ emissions with future changes in atmospheric $\mathrm{CO}_{2}$ concentration and hence climate (e.g., Prentice et al. 2001). Including the carbon cycle as 
an interactive component in comprehensive climate models has become common, and the Coupled Carbon Cycle Climate Model Intercomparison Project ( $\mathrm{C}^{4} \mathrm{MIP}$; Friedlingstein et al. 2006) presented results of 11 such models. All models participating in the $\mathrm{C}^{4} \mathrm{MIP}$ study showed an increase in future atmospheric $\mathrm{CO}_{2}$ concentration for the same anthropogenic emissions because of positive feedbacks of climate on natural carbon sinks (albeit neglecting nitrogen cycle processes). However, this comparison of models also showed large quantitative uncertainty in the magnitude of this effect. This large range in future carbon uptake seen between models also exists because of parameter uncertainty within single models (Booth et al. 2012).

Such coupled climate-carbon cycle models simulate the natural exchange of carbon by the land and ocean with the atmosphere and thus provide a predictive link between emissions and atmospheric concentrations of $\mathrm{CO}_{2}$. In emissions-driven simulations such as in $\mathrm{C}^{4} \mathrm{MIP}$, these models calculate changes in atmospheric $\mathrm{CO}_{2}$ concentration given a scenario of emissions. They can also be used to compute the emissions required to follow a prescribed concentration pathway (Jones et al. 2006; Matthews 2006; Plattner et al. 2008). This method has become widespread and was recommended by Hibbard et al. (2007) as the experimental design for phase 5 of the Coupled Model Intercomparison Project (CMIP5; http://cmip-pcmdi.llnl.gov/cmip5/index.html) and has subsequently been used to present compatible emissions from individual models for the CMIP5 scenarios (Arora et al. 2011). Johns et al. (2011) also used this approach to quantify the uncertainty in compatible emissions across an ensemble of models that had performed simulations under the same $\mathrm{CO}_{2}$ pathway.

The latest generation of state-of-the-art Earth system general circulation models (ES-GCMs) has recently been used to carry out simulations of a new set of scenarios for CMIP5 (Taylor et al. 2012; Moss et al. 2010). The CMIP5 simulations include four future socioeconomic scenarios referred to as representative concentration pathways (RCPs; Moss et al. 2010; van Vuuren et al. 2011): RCP2.6, RCP4.5, RCP6.0, and RCP8.5. These future scenarios include a $\mathrm{CO}_{2}$ concentration pathway computed to be consistent with anthropogenic carbon emissions as generated by four integrated assessment models (IAMs). The RCPs are labeled according to the approximate global radiative-forcing level at 2100 with $\mathrm{CO}_{2}$ concentrations reaching 421, 538, 670, and 936 ppm, respectively (Fig. 1a). The RCP2.6 $\mathrm{CO}_{2}$ pathway peaks at a concentration of $443 \mathrm{ppm}$ at 2050 before declining in the latter half of the century and is alternatively known as RCP3 peak and decline (RCP3PD).
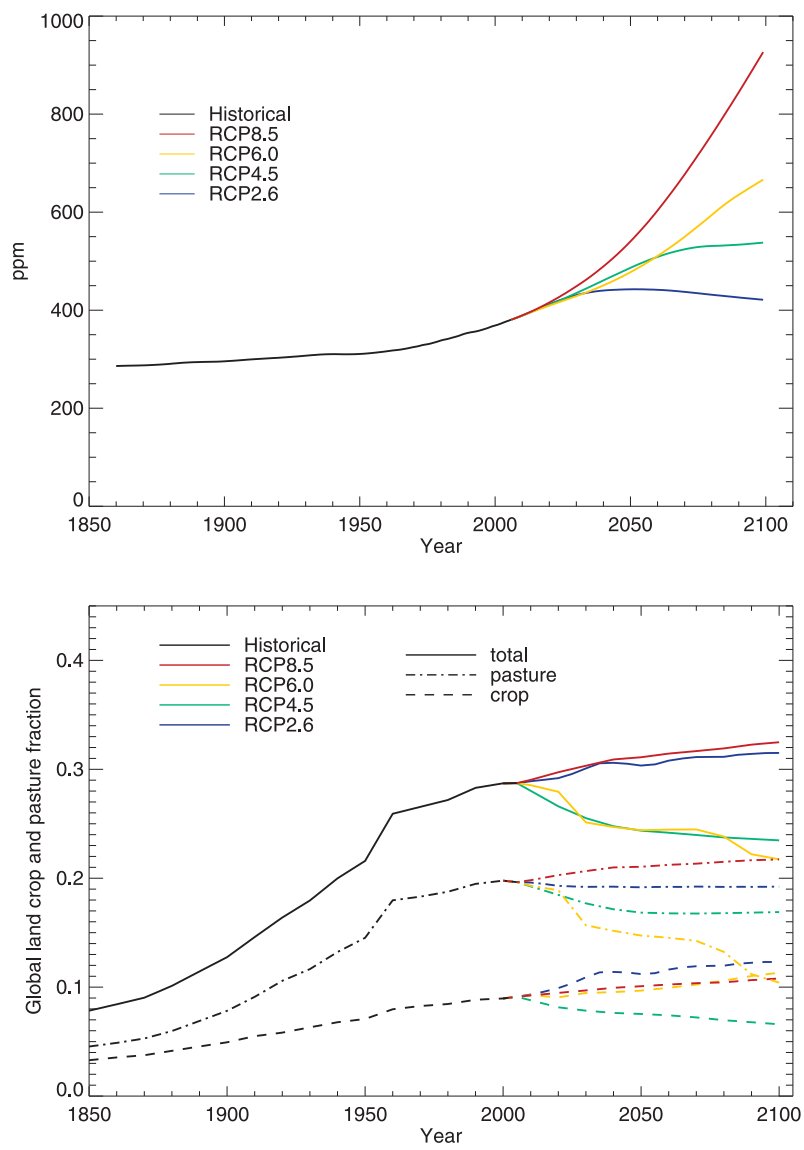

FIG. 1. RCP scenarios of (a) atmospheric $\mathrm{CO}_{2}$ concentration and (b) anthropogenic land-use change for the historical period and future RCP scenarios. Plotted for the land-use scenarios are the fractions of global land area occupied by crops (dashed lines), pasture (dotted-dashed lines), and their total (solid lines).

Within the socioeconomic scenarios that drive the RCPs, representation of climate policy has been included to enable the scenario to achieve the target radiative forcing by 2100. A simple climate-carbon cycle model was then used to calculate atmospheric $\mathrm{CO}_{2}$ concentration from the scenario emissions (Meinshausen et al. 2011). IAMs' estimates of future economic activities, including land-use changes, are driven by simplified, often regional models of future climate and carbon cycle, which are substantially different from those in ESGCMs. The complexity and high degree of uncertainty in resolving biosphere-climate interactions (Friedlingstein et al. 2006; Johns et al. 2011) makes it important to establish consistency between the two modeling frameworks. A key step in establishing consistency between the frameworks is the comparison of compatible emissions diagnosed from the CMIP5 $\mathrm{CO}_{2}$ concentrationdriven ES-GCM experiments, to the emissions generated by the IAMs. 
Especially of interest for very low mitigation scenarios, such as RCP2.6, are quantification of short-term emissions reductions required and the question of whether the scenario is achievable without the requirement of longterm globally negative emissions, which might only be possible with the use of large-scale deliberate carbon dioxide removal and storage. Use of the CMIP5 range of ES-GCMs also enables us to estimate the uncertainty in the compatible emissions to follow a given radiativeforcing pathway. The process of scenario development is intended to be iterative (Moss et al. 2010), so these results will inform subsequent development and calibration of IAMs.

Land-use change has a profound influence on both biophysical features of the land and also its carbon storage, adding $156 \mathrm{PgC}$ to the atmosphere from 1850 to 2005. Past land-use changes have been influential in emitting $\mathrm{CO}_{2}$ to the atmosphere (Houghton 2008; Denman et al. 2007) and future changes in land use will continue to strongly perturb the terrestrial carbon cycle and may also be used deliberately to try to mitigate climate change through reduced emissions (e.g., REDD; Gullison et al. 2007). Land-use trajectories in the four RCP scenarios show very distinct trends and cover a wide range of projections (see Fig. 1b). The area of cropland and pasture increases in RCP8.5, mostly driven by an increasing global population, but cropland area also increases in the RCP2.6, despite a smaller population increase, as a result of increased bioenergy production used for climate mitigation. RCP6.0 shows an increasing use of cropland but a decline in pasture land. RCP4.5 is the only scenario to show a decrease in global cropland. There is not a monotonic progression from "low" to "high" land use through the scenarios in the same way that there is for radiative forcing and the impact of this will be shown to be important for future changes in the fraction of emissions taken up by land. Land-use emissions of $\mathrm{CO}_{2}$ are fundamentally different from fossil-fuel emissions, which add a new supply of $\mathrm{CO}_{2}$ to the atmosphere-land-ocean system, whereas land-use emissions merely relocate carbon from one component to another within this system. We describe in the methods section (section 2) that, when diagnosing permissible emissions from ES-GCMs, fossil-fuel emissions can be easily diagnosed as changes in the total carbon held in the simulated atmosphere-land-ocean system. Land-use emissions, however, are harder to diagnose within the ES-GCMs.

Section 2 describes the models and methods used in the analysis and section 3 presents results of future changes in land and ocean carbon uptake and the diagnosed compatible fossil-fuel emissions and their airborne fraction. Discussion and conclusions follow in section 4.

\section{Experiments and methods}

\section{a. CMIP5 experimental design}

The CMIP5 experimental design is described in Taylor et al. (2012) and was discussed in Hibbard et al. (2007). The simulations presented here are the future (twenty-first century) RCP simulations (CMIP5 experiments 4.1-4.4), which are "concentration driven" rather than "emissions driven." In these simulations, the time evolution of atmospheric $\mathrm{CO}_{2}$ is specified and the simulated exchange of carbon between the atmosphere and the underlying land and ocean allows us to diagnose anthropogenic emissions that are compatible with the prescribed concentration pathway. This approach has been used before for simplified models (e.g., Prentice et al. 2001), but CMIP5 is the first time it has been used for a coordinated set of experiments for multiple ES-GCMs.

The CMIP5 models are run using prescribed inputs of atmospheric $\mathrm{CO}_{2}$ (Fig. 1a), other greenhouse gases, aerosols, and natural forcings such as solar and volcanic aerosol emissions. Scenarios of land-use change are also available (Fig. 1b), but their implementation differs considerably between models or, in two cases considered here, is not represented at all.

\section{b. Compatible emissions diagnosis}

Studies that have used this approach in the past to estimate compatible emissions have only discussed the resulting emissions in the context of total anthropogenic emission and not a breakdown into fossil or land-use emissions (Jones et al. 2006; Matthews 2006; Plattner et al. 2008). The models used in those studies did not include any direct effect of land use or human disturbance on land carbon storage or land-cover characteristics, and so diagnosis of total emissions was all that could be achieved. For the CMIP5 simulations, many models now include representation of the effect of land-use disturbance on the terrestrial carbon cycle making, in principle, diagnosis of emissions possible from both fossil-fuel use and land-use change. However, because of a multitude of different land-use processes being included or excluded from different models and the number of different possible definitions of "land-use emission," it is very difficult to clearly present land-use emissions from these simulations. Arora and Boer (2010) discuss some of the issues and challenges of defining and quantifying uncertainty in land-use emissions. In the appendix, we show that, regardless of difficulties in diagnosing the land-use emission component, the simulations can be used to diagnose the fossil-fuel component of the compatible emissions and compare with IAM/RCP values.

For the combined atmosphere-land-ocean system, the rate of change of carbon may be written as 


$$
\frac{d C_{\mathrm{Tot}}}{d t}=\frac{d C_{A}}{d t}+\frac{d C_{L}}{d t}+\frac{d C_{O}}{d t}=E_{F},
$$

where $C_{\mathrm{Tot}}=C_{A}+C_{L}+C_{O}$ is the sum of carbon in the atmosphere, land, and ocean components (the latter including seafloor sediments) and $E_{F}$ is an external addition of carbon into the atmosphere such as from anthropogenic fossil-fuel burning. The equations for the atmosphere, land, and ocean are

$$
\begin{aligned}
\frac{d C_{L}}{d t} & =F_{L}=F_{L, \mathrm{NAT}}-E_{\mathrm{LUC}} \\
\frac{d C_{O}}{d t} & =F_{O} \\
\frac{d C_{A}}{d t} & =F_{A}+E_{F} \\
& =-F_{L}-F_{O}+E_{F} \\
& =-F_{L, \mathrm{NAT}}-F_{O}+\left(E_{F}+E_{\mathrm{LUC}}\right)
\end{aligned}
$$

where $\left(F_{L}+F_{O}\right)=-F_{A}$ are the fluxes between the atmosphere and the underlying land and ocean, taken to be positive into the components. The atmosphere-land $\mathrm{CO}_{2}$ flux is made up of natural atmosphere-land $\mathrm{CO}_{2}$ flux $F_{L, \text { NAT }}$ and anthropogenic land-use change $E_{\mathrm{LUC}}$ components and total emissions $E_{T}$ are thus given by $E_{T}=E_{F}+E_{\mathrm{LUC}}$.

Integrating Eqs. (1) and (2) from initial time to $t$ gives

$$
\Delta C_{\mathrm{Tot}}=\Delta C_{A}+\Delta C_{L}+\Delta C_{O}=\int_{0}^{t} E_{F} d t=\tilde{E}_{F},
$$

where $\tilde{E}_{F}$ is the cumulative fossil-fuel input to the system. Division by $\tilde{E}_{F}$ yields all terms in fractional form

$$
f_{A}+f_{L}+f_{O}=1,
$$

where $f_{A}$ is the airborne fraction of cumulative fossilfuel emissions and $f_{L}$ and $f_{O}$ are fractional cumulative fossil-fuel emissions taken up by the land and ocean.

The land-use scenario and how it is implemented in ESGCMs affects the land carbon pools and thus the diagnosed $E_{F}$, but land-use emissions themselves cannot be measured from these simulations alone. To diagnose $E_{\mathrm{LUC}}$ it would be necessary to repeat the simulations without land-use disturbance and compare the different evolution of $C_{L}$ with and without land use (see, e.g., Arora and Boer 2010). This definition of $E_{\mathrm{LUC}}$ would be different from the direct deforestation emissions that some models can diagnose and also differs in definition from historical reconstructions such as by Houghton (2008), who uses a constant (non-time-varying assumption of $T$ and $\mathrm{CO}_{2}$ ) baseline condition against which to measure emissions. Not all the ES-GCMs use the full range of information available from the land-use change scenarios such as wood harvest projections, subgrid-scale shifting cultivation, or representation of primary and secondary forests; these processes can have a bigger impact than the choice of RCP land-use scenario (Hurtt et al. 2011).

To diagnose carbon emissions from land-use additional ES-GCM experiments will be necessary. These experiments therefore are a research priority and are the focus of the Land-Use and Climate, Identification of Robust Impacts (LUCID)-CMIP5 experiment (Brovkin et al. 2013). From here on, this paper deals only with the diagnosed fossil-fuel emissions. It remains an important research gap to be able to quantify land-use carbon emissions from these ES-GCMs in a reliable, consistent, and well-defined way.

\section{c. Model output data}

Land surface models typically partition carbon into various pools such as different types of living tissue or ages of soil carbon or harvested/stored wood products. To facilitate intercomparison, the CMIP5 data request was for models to aggregate their own component pools into four common outputs, whose short network Common Data Form (NetCDF) output names are as follows:

- cVeg, carbon stored in living biomass (both above and below ground);

- cSoil, carbon stored as dead organic matter in mineral soils;

- cLitter, freshly dropped dead organic carbon before it is incorporated into the soil carbon; and

- cProduct, carbon stored in wood products (including anything from paper to furniture).

In our analysis we make use of standard CMIP5 output from the Program for Climate Model Diagnosis and Intercomparison (http://pcmdi3.llnl.gov/esgcet/home. $\mathrm{htm}$ ) as provided by the models listed in Table 1 . Not all models have performed all the RCP simulations, so we use data available at the time of writing as listed in Table 1. Not all models include all of these pools, but for each model the total terrestrial carbon $C_{L}$ is calculated as the sum of all available land pools.

All but two of these models (INM-CM4.0 and BCCCSM1.1) include representation of anthropogenic landuse change in these simulations. While data are available for these two models, which would allow calculation of compatible emissions, the influence of land-use on terrestrial carbon stores as described above means this would not allow a like-for-like comparison. Hence, we have shown results from these models for comparison as dashed lines in figures showing land and ocean carbon changes, but we omit them from the comparison of compatible emissions. 


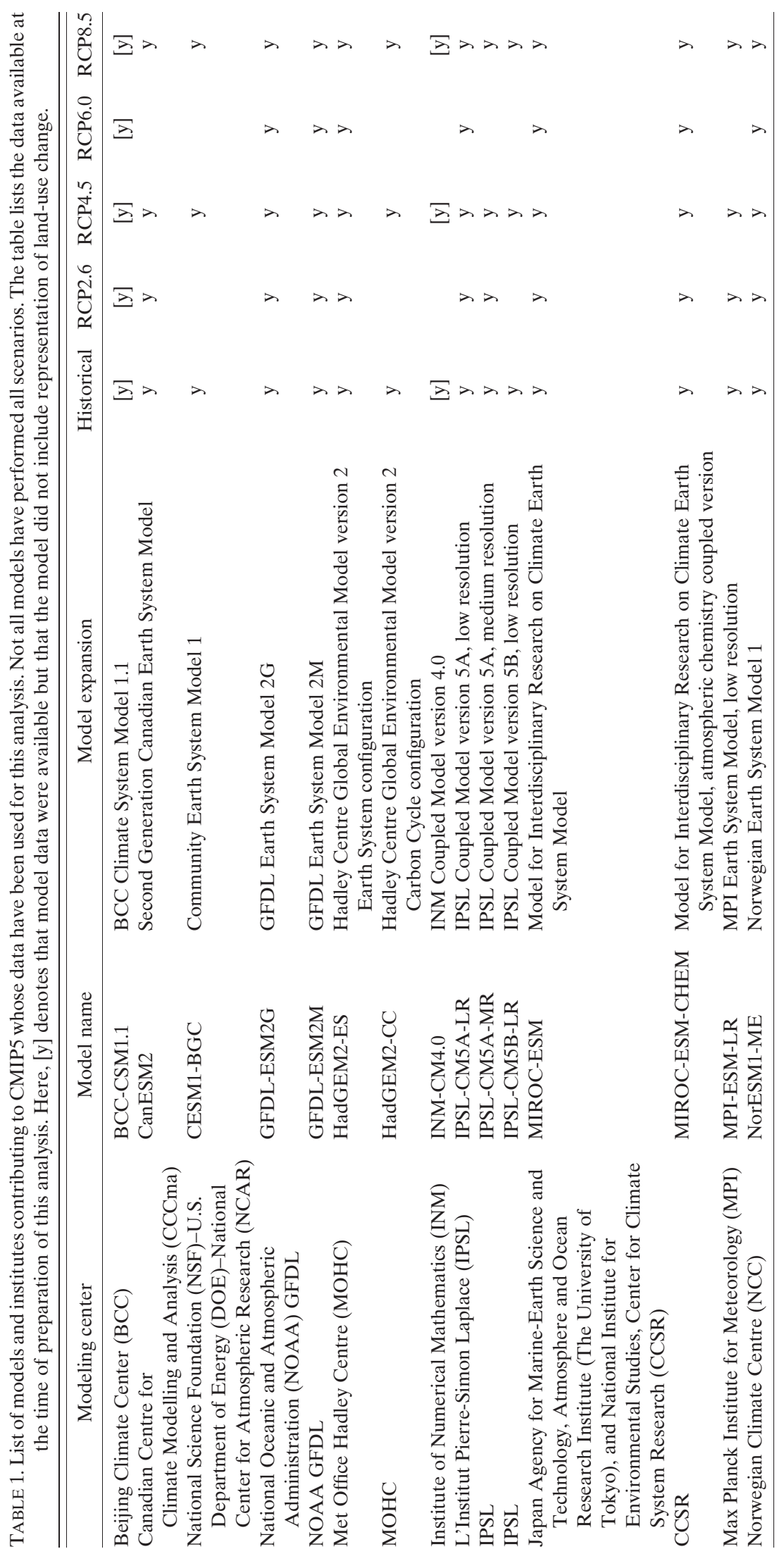


Total land carbon
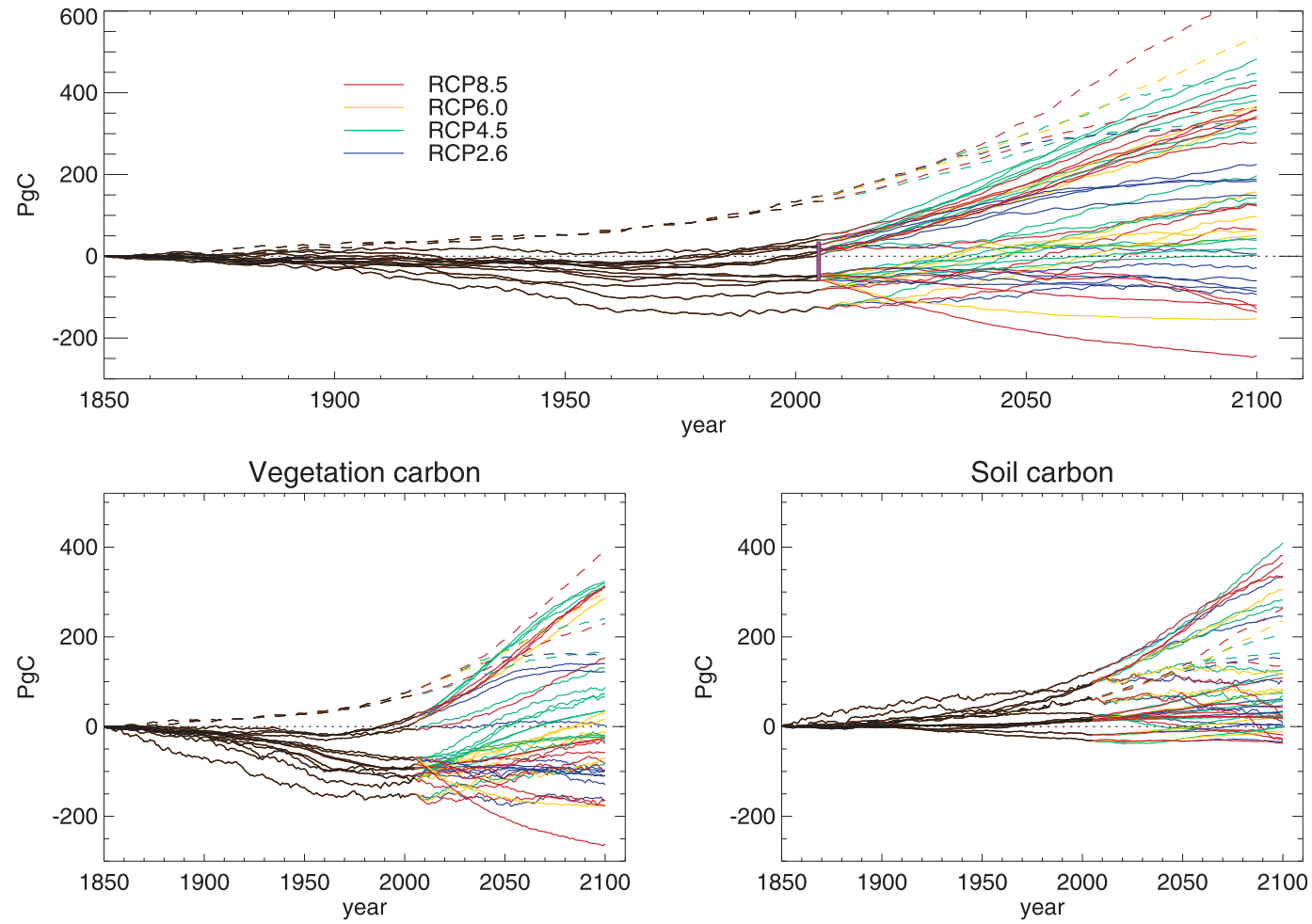

FIG. 2. Changes in (top) total land carbon store, (bottom left) vegetation carbon, and (bottom right) soil carbon (defined as cSoil + cLitter) for the CMIP5 models. An observationally derived estimate of net changes (Arora et al. 2011) is shown by the vertical pink bar in (top). Dashed lines represent output from ES-GCMs without representation of land-use change (INM-CM4.0 and BCC-CSM1.1).

The initial size of these pools is poorly constrained by observations and varies substantially across models, with preindustrial vegetation and soil carbon ranging from 410 to $890 \mathrm{PgC}$ and from 500 to $2930 \mathrm{PgC}$, respectively, across models. Todd-Brown et al. (2013) have evaluated soil carbon simulations from CMIP5 models and find a wide range of model abilities to recreate observed distributions of soil carbon. In our analysis, it is changes in storage that are important for diagnosing compatible emissions. It is not yet known to what extent errors in the initial state have an influence on future projections.

For ocean carbon storage, we use the CMIP5 reported values of air-to-sea flux fgco 2 and integrate this over time to give a change in ocean storage. For atmospheric $\mathrm{CO}_{2}$, we use the globally uniform concentration ( $\mathrm{ppm}$ ) provided by the RCP scenarios and multiply it by $2.12 \mathrm{PgC} \mathrm{ppm}^{-1}$ to obtain the atmospheric carbon burden $C_{A}(\mathrm{PgC})$.

\section{Results}

\section{a. Changes in land carbon uptake and storage}

Figure 2 shows changes in the total land carbon storage (Fig. 2a) and individual changes in vegetation and soil (Figs. 2b,c), where we have combined here cSoil and cLitter. Carbon stored in wood products is generally small (less than $10 \mathrm{PgC}$ ) and so contributes little to the total storage or its changes for most models. The exceptions are the Geophysical Fluid Dynamics Laboratory (GFDL) models, which include more detailed treatment of land-use transitions and also consideration of land-use changes from 1700 to 1850 , leading to greater cProduct values. There is a large spread in model response for both historical and future periods. Most models show a decline since preindustrial due to increasing areas of deforestation, followed by a recovery in the final decades of the twentieth century, attributed mainly to $\mathrm{CO}_{2}$ fertilization. This is in qualitative agreement with observational estimates (Trudinger et al. 2002), although there is much uncertainty over the magnitude. All models that include land-use changes show some decline in vegetation carbon at least in the early part of the simulation, but those which exclude land-use change (INM-CM4.0 and BCC-CSM1.1) simulate a steady increase in land carbon during the twentieth century. Spread of changes in land carbon storage across the models, which represent land-use change, ranges from -124 to $+50 \mathrm{PgC}$ by 2005 , consisting of 

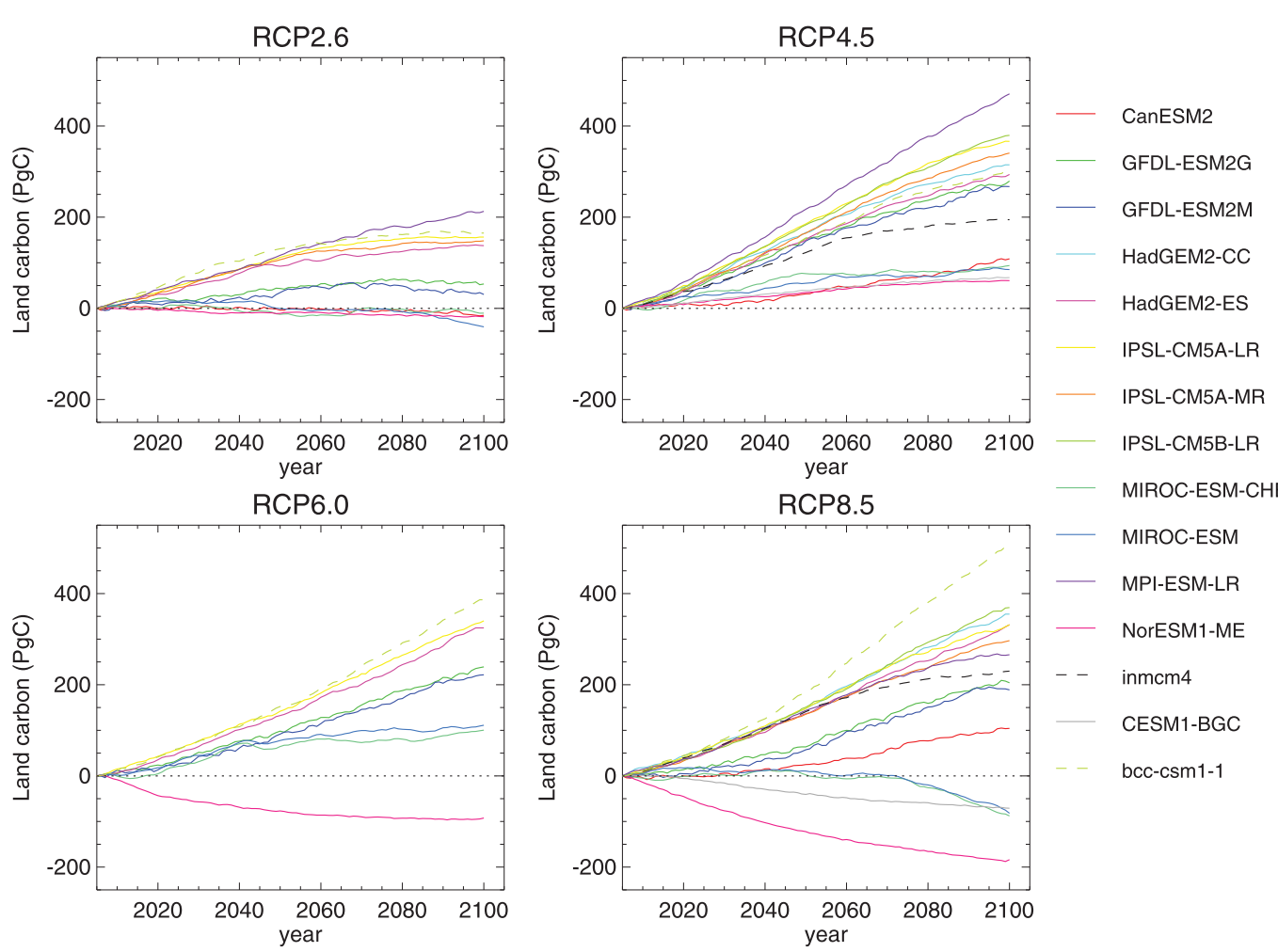

MIROC-ESM-CHEM

MIROC-ESM

— MPI-ESM-LR

NorESM1-ME

- - inmcm4

CESM1-BGC

bcc-csm1-1

FIG. 3. As in Fig. 2a, but from 2005, shown separately for each RCP scenario. Individual models are denoted in separate colors for comparison across scenarios. Dashed lines represent output from ES-GCMs without representation of land-use change (INM-CM4.0 and BCC-CSM1.1).

from -151 to $+27 \mathrm{PgC}$ from vegetation and from -31 to $+120 \mathrm{PgC}$ from soil (including litter) carbon.

Arora et al. (2011) estimate the observation-based cumulative historical (1850-2005) land carbon uptake, which is difficult to observe directly, as $-11 \pm 47 \mathrm{PgC}$ (i.e., a source to the atmosphere) as the residual of the observed change in atmospheric carbon burden and cumulative fossil-fuel emissions based on the CMIP5 dataset and observation-based estimates of cumulative ocean carbon uptake based on Sabine and Feely (2007) up to 1999 and extended to 2005 using values from Denman et al. (2007). The wide range in historical land carbon uptake among models is the result of intermodel uncertainty in both the strength of the $\mathrm{CO}_{2}$ fertilization effect (Arora et al. 2013) as well as differences in the manner they implement land-use change. This estimate of net land carbon change is very close to the multimodel mean of $-19 \mathrm{PgC}$, and the range encompasses 9 out of 13 models (Fig. 2), although this cannot be partitioned into changes in vegetation and soil carbon separately. Only one model falls outside twice this observational uncertainty: GFDL-ESM2M simulates a loss of $124 \mathrm{PgC}$.

Cumulative land carbon uptake for the future duration shows similar large intermodel spread, which overwhelms the interscenario spread. Figure 3 shows each scenario separately, anomalized relative to 2005 to better show the future changes in each scenario clearly. For RCPs 2.6 and 8.5 , which both include increasing areas of land use in their scenario, four models project decreases in future land carbon storage, although most models project an increase. For RCPs 4.5 and 6.0, whose scenarios include decreasing areas of land use, all models agree on future increases in land carbon storage, although with large spread, with RCP4.5 showing the largest values of land carbon accumulation.

At present, it is not easy to quantify the impact of land use on the terrestrial carbon cycle within a single model without carrying out multiple simulations. These simulations are being carried out by some groups as part of the LUCID-CMIP5 activity but are not part of the standard CMIP5 protocol (Brovkin et al. 2013).

\section{b. Changes in ocean carbon uptake and storage}

Whether expressed as annual fluxes (Fig. 4, top) or cumulative changes in inventory (Fig. 4, bottom), ocean carbon storage shows a consistent picture for each RCP across most ES-GCMs. Oceanic uptake is driven primarily by $\Delta p \mathrm{CO}_{2}$ (the gradient of $\mathrm{CO}_{2}$ concentration between atmosphere and ocean), so for higher $\mathrm{CO}_{2}$ 


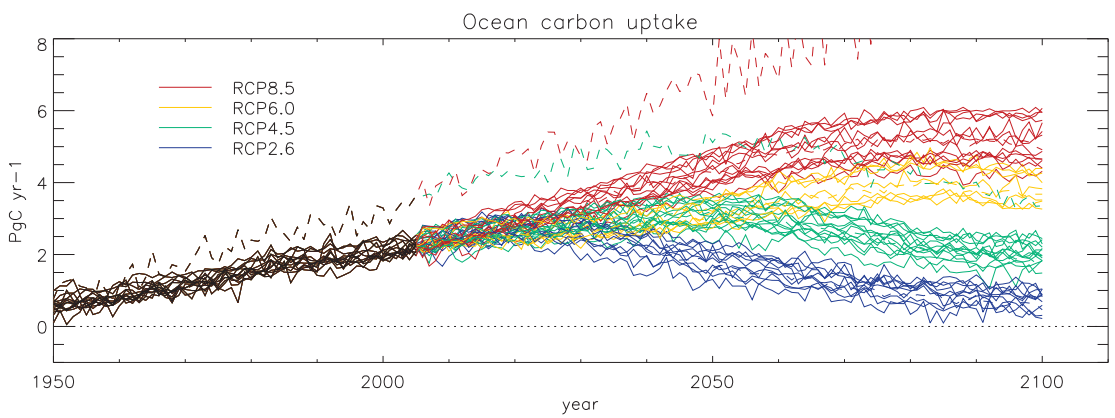

Cumulative ocean uptake

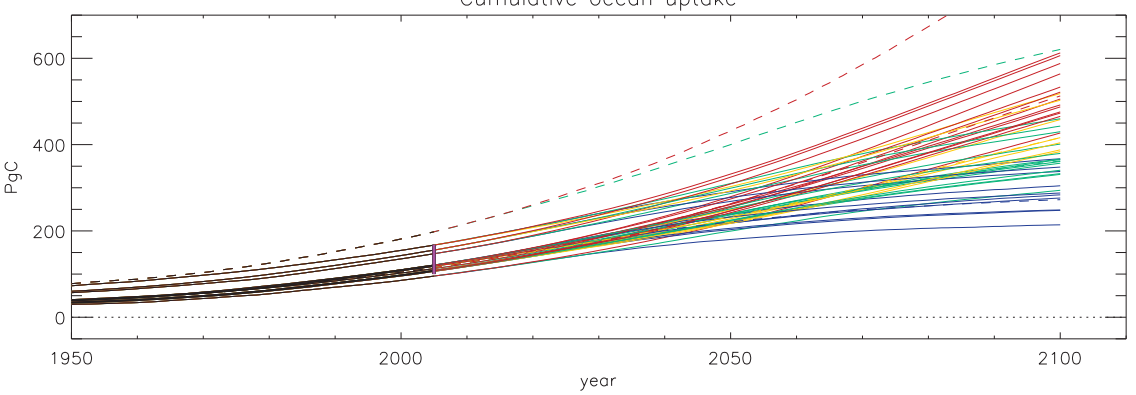

FIG. 4. Changes in annual (top) oceanic carbon uptake and (bottom) cumulative uptake since 1850 from the CMIP5 models. An observationally derived estimate of net changes (Arora et al. 2011; C. Le Quéré 2012, personal communication) is shown by the vertical pink bar in (bottom). For consistency with Figs. 2 and 3, dashed lines represent output from ES-GCMs without representation of land-use change (INM-CM4.0 and BCC-CSM1.1). For better visibility of the near past and the twenty-first century, the $x$ axis begins here at 1950 .

concentration pathways all models simulate greater ocean carbon uptake. Observationally constrained estimates for cumulative oceanic uptake from 1850 to 2005 are $125 \pm 25 \mathrm{PgC}$ [based on the Ocean Carbon-Cycle Model Intercomparison Project (OCMIP) process-based global ocean biogeochemical models forced by observed meteorological fields; C. Le Quéré 2012, personal communication] and $141 \pm 27 \mathrm{PgC}$ (Arora et al. 2011). These estimates of net oceanic uptake are very close to the multimodel mean of $127 \mathrm{PgC}$ and the combined range (100-168 PgC) encompasses 13 out of 15 models (Fig. 4). CanESM2 falls just below this range with 95.3-PgC uptake, and INM-CM4.0 falls outside twice this observational uncertainty with $198-\mathrm{PgC}$ uptake. INM-CM4.0 also falls outside the envelope of behavior of the other models and has significantly large interannual variability (see Fig. 4). Analysis of the reasons for this is beyond the scope of this study, but we note that INM-CM4.0 is excluded from our compatible emissions comparison as described above owing to it not representing land-use change.

Under increasing rates of $\mathrm{CO}_{2}$ rise in the $\mathrm{RCP} 8.5$ scenario, models simulate continuing increases in oceanic carbon for most of the century before beginning to level out by 2100 , whereas for the peak-and-decline $\mathrm{RCP} 2.6$ scenario uptake reduces to close to zero. In the
$\mathrm{RCP} 4.5$ scenario, atmospheric $\mathrm{CO}_{2}$ initially exceeds that in the RCP6.0 and hence so do ocean carbon fluxes, although by 2100 uptake under RCP6.0 has increased to exceed that in RCP4.5.

Unlike for cumulative land uptake, intermodel spread within a scenario is typically smaller than the interscenario spread of the model means and so the clusters of simulations for each scenario tend not to overlap much. This is in agreement with feedback analysis of the idealized $1 \% \mathrm{yr}^{-1} \mathrm{CO}_{2}$ simulations by Arora et al. (2013). They show that the differences in the modeled responses of the carbon budget to changes in $\mathrm{CO}_{2}$ and climate are 3-4 times larger for the land components than the ocean components and that the CMIP5 generation of ES-GCMs appear to show closer consensus in their future oceanic uptake than did the $\mathrm{C}^{4} \mathrm{MIP}$ carbon cycle models, although the experimental design differs slightly.

\section{c. Compatible fossil-fuel emissions}

Figure 5 and Table 2 present the diagnosed compatible fossil-fuel emissions based on Eqs. (1) and (2) for the historical and the twenty-first century from the CMIP5 ES-GCMs. For both the twentieth and twenty-first centuries, the multimodel mean fossil-fuel emissions from the ES-GCMs compare well with the observation-based 

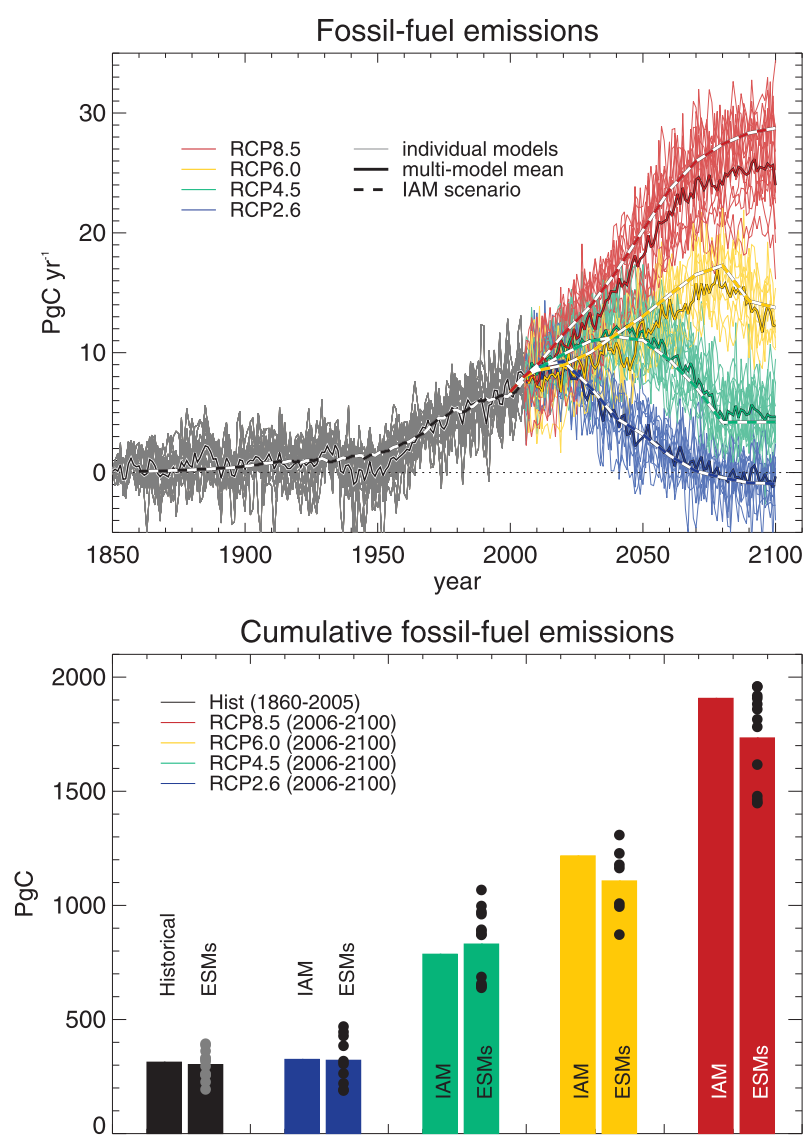

FIG. 5. Compatible fossil-fuel emissions from CMIP5 models for the historical period (black) and the four RCP scenarios for the twenty-first century (colors). (top) Time series of annual emissions: the thick solid lines denote the multimodel mean and the thick dashed lines the historical and RCP scenarios. Individual model estimates are shown in the thin lines. (bottom) Cumulative emissions for historical (1850-2005) and twenty-first century (2006-2100). The left-hand bars in each pair show the cumulative emissions from the historical reconstruction or from the RCP scenario as generated by IAM models, and the right-hand bars the CMIP5 multimodel mean. Black/gray circles show individual model values.

estimates for the historical period and with the emissions the four IAMs generated for each scenario. In the high-end scenarios, RCP8.5 and to a lesser extent RCP6.0, the CMIP5 models on average project lower compatible emissions than the IAMs. This indicates that the sensitivity to climate warming, which leads to reduced natural carbon uptake (Friedlingstein et al. 2006; Arora et al. 2013), is stronger in ES-GCMs than in the IAMs under higher levels of climate change.

The RCP pathways of $\mathrm{CO}_{2}$ concentration were generated using the Model for the Assessment of GreenhouseGas-Induced Climate Change (MAGICC6) calibrated to represent the median of CMIP3 climate models and $\mathrm{C}^{4} \mathrm{MIP}$ carbon cycle responses (Meinshausen et al. 2011).
TABLE 2. Compatible fossil-fuel emissions for the historical period and future scenarios as provided by IAMs and as simulated by CMIP5 models. Values ( $\mathrm{PgC})$ are rounded to the nearest whole number, and are for the following periods: 1850-2005 (historical) and 2006-2100 (RCPs). The standard deviation across models as well as the full minimum-maximum model range is also given.

\begin{tabular}{lrrrrr}
\hline \hline & & \multicolumn{3}{c}{ CMIP5 models } \\
\cline { 3 - 6 } & & & & & \\
\cline { 3 - 6 } & & & & & \\
Historical & & 313 & 303 & 61 & $194-394$ \\
RCP, 2006-2100 & 2.6 & 325 & 322 & 106 & $189-469$ \\
& 4.5 & 786 & 831 & 155 & $640-1068$ \\
& 6.0 & 1217 & 1107 & 153 & $872-1308$ \\
& 8.5 & 1907 & 1734 & 209 & $1448-1959$ \\
\hline
\end{tabular}

Friedlingstein et al. (2012, manuscript submitted to $J$. Climate) show a similar systematic difference between the RCP $\mathrm{CO}_{2}$ concentrations and the CMIP5 models in the emissions-driven RCP8.5 simulation and attribute this to greater ocean uptake in the MAGICC6 calibration, caused by one or two models in the $\mathrm{C}^{4} \mathrm{MIP}$ ensemble having excessive ocean carbon uptake. The CMIP5 models show greater consensus in ocean uptake and this may explain the difference between CMIP5 compatible emissions and the RCP $\mathrm{CO}_{2}$ pathways.

The RCP2.6 scenario represents an aggressive mitigation scenario aimed at limiting global radiative forcing to be as low as possible by 2100 . Here, we assess results from the 10 ES-GCMs that performed this scenario in the context of the achievability of the scenario in terms of the emissions reduction required to follow the $\mathrm{CO}_{2}$ concentration pathway. We look at implied at midcentury emissions reductions targets and the longerterm implications for the eventual level of emission reductions required by the end of the century. Table 3 shows the compatible fossil-fuel emissions as simulated by the models for decades centered on 1990 and 2050 for RCP2.6, along with the percentage reduction in emissions required by 2050 from 1990 levels to achieve the RCP2.6 peak-and-decline pathway. There is a very large spread in the required percentage reductions by 2050 , with values ranging from $14 \%$ to $96 \%$ for the available models. The average 2050 emissions from these models show a requirement for $50 \%$ reductions from the average 1990 emissions.

A key question is whether or not global net negative emissions are required to achieve the target $\mathrm{CO}_{2}$ pathway in this scenario. Because of interannual variability (largely in the land uptake), many models simulate occasional negative fossil-fuel emissions in some years by 2100 , but a more relevant measure is the requirement for long-term average negative emissions. The 10 CMIP5 models analyzed here disagree on this (Fig. 6a). 
TABLE 3. Compatible fossil-fuel emissions for the two decades centered on 1990 (1985-95) and 2050 (2045-55) for the 10 models that have supplied enough data to calculate compatible emissions for the RCP2.6. The final column shows the percentage reduction from 1990 levels required by 2050 to achieve the RCP2.6 $\mathrm{CO}_{2}$ concentration pathway.

\begin{tabular}{lllc}
\hline \hline \multicolumn{1}{c}{ Model } & \multicolumn{1}{c}{$\begin{array}{c}\text { 1990s } \\
\text { emissions }\end{array}$} & $\begin{array}{c}\text { 2050s } \\
\text { emissions }\end{array}$ & $\begin{array}{c}\% \\
\text { reduction }\end{array}$ \\
\hline CanESM2 & 5.15 & 1.66 & 68 \\
GFDL-ESM2G & 5.16 & 3.11 & 40 \\
GFDL-ESM2M & 6.16 & 3.71 & 40 \\
HadGEM2-ES & 5.67 & 3.05 & 46 \\
IPSL-CM5A-LR & 6.52 & 4.76 & 27 \\
IPSL-CM5A-MR & 7.15 & 4.55 & 36 \\
MIROC-ESM-CHEM & 5.75 & 0.54 & 91 \\
MIROC-ESM & 4.69 & 0.17 & 96 \\
MPI-ESM-LR & 6.23 & 5.38 & 14 \\
BCC-CSM1.1 & 5.12 & 2.30 & 55 \\
Model mean & $5.76 \pm 0.8$ & $2.92 \pm 1.8$ & 50 \\
Historical & $6.4 \pm 0.5$ & &
\end{tabular}

To follow the prescribed decrease in atmospheric $\mathrm{CO}_{2}$ from 443 to 421 ppm, 6 out of 10 models (CanESM2, GFDL-ESM2G, GFDL-ESM2M, MIROC-ESM-CHEM, MIROC-ESM, and BCC-CSM1.1) simulate the need for negative emissions on average from 2080 to 2100 while the other 4 (HadGEM2-ES, IPSL-CM5A-LR, IPSLCM5A-MR, and MPI-ESM-LR) achieve the scenario without the need for sustained negative emissions. Model CanESM2 projects a requirement for sustained negative emissions from as early as 2060 . The six models projecting negative emissions (paler blue in Fig. 6) are consistently lower and with an earlier peak than the four models that do not. They are slightly below the 1990s observed emissions, while the four models projecting sustained positive emissions are slightly above the 1990s estimate. Hence, there is no clear observational constraint on which set of models is more likely to be reliable.

Figure $6 \mathrm{~b}$ demonstrates additionally if following the RCP2.6 concentration pathway also achieves the commonly cited climate target of restricting warming below $2^{\circ} \mathrm{C}$ above preindustrial levels. The vertical axis shows the peak twenty-first-century warming and the horizontal axis the average fossil-fuel emission level for the final $20 \mathrm{yr}, 2080-2100$. As described above, some models show a requirement for net negative emissions and some do not. Similarly, some models simulate global temperature increase above $2^{\circ} \mathrm{C}$ and some below. Two models, HadGEM2-ES and MPI-ESM-LR, predict that global temperatures can be kept below $2^{\circ} \mathrm{C}$ warming without the need for negative emissions. Three models, CanESM2 and the two MIROC-ESM variants, show that even with global negative emissions global temperatures may still exceed $2^{\circ} \mathrm{C}$.
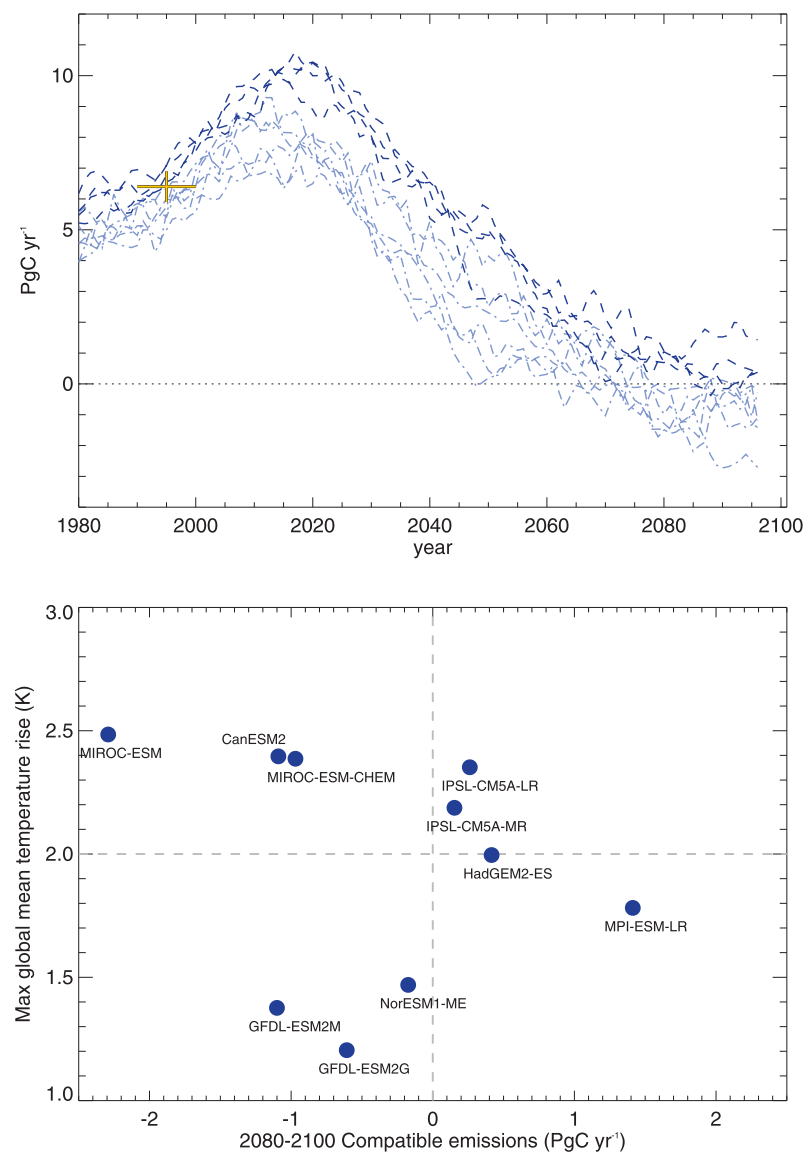

FIG. 6. Compatible fossil-fuel emissions for the peak-and-decline RCP2.6 scenario. (a) Plotted with 10-yr smoothing from CMIP5 models: CanESM2, GFDL-ESM2G, GFDL-ESM2M, MIROCESM-CHEM, MIROC-ESM, and NorESM1-ME require sustained negative emissions beyond 2080 and are shown in paler blue dotteddash lines, and HadGEM2-ES, IPSL-CM5A-LR, IPSL-CM5A-MR, and MPI-ESM-LR are shown in darker blue dashed lines. Historical fossil-fuel emissions for the 1990s are shown by the black and yellow bar. (b) The 20-yr end-of-century average compatible emissions (2080-2100) ( $x$ axis) against peak twenty-first-century warming, defined as maximum of 10-yr running mean above preindustrial ( $y$ axis).

It remains uncertain therefore, both whether or not the RCP2.6 concentration pathway will restrict global temperatures to below $2^{\circ} \mathrm{C}$ above preindustrial. It is also uncertain whether this concentration pathway is achievable without the need for active carbon sequestration to globally exceed residual fossil-fuel carbon emissions.

\section{d. Future changes in the airborne fraction}

The airborne fraction (AF) of anthropogenic $\mathrm{CO}_{2}$ emissions is commonly quoted as an instantaneous quantity as the ratio of the change in atmospheric $\mathrm{CO}_{2}$ for a year to the emissions in that year, although it can also be calculated as a cumulative fraction over a longer 
(a)

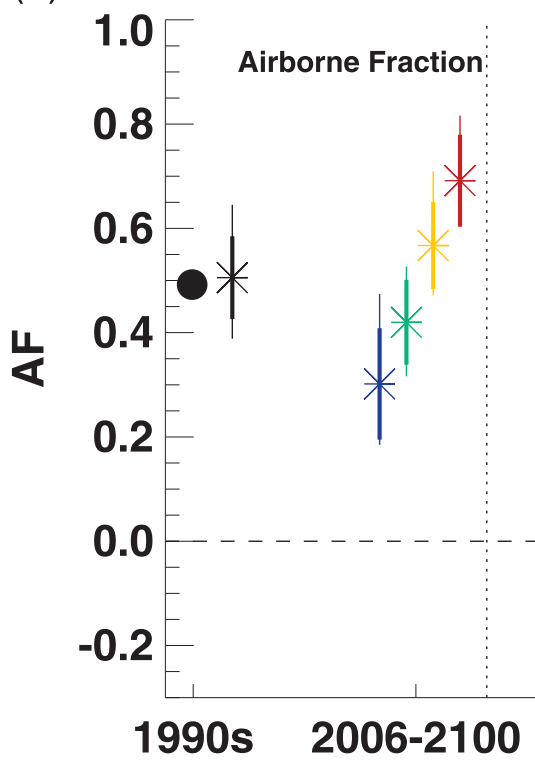

(b)

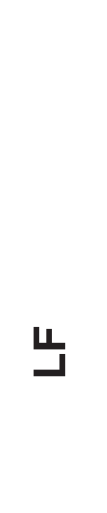

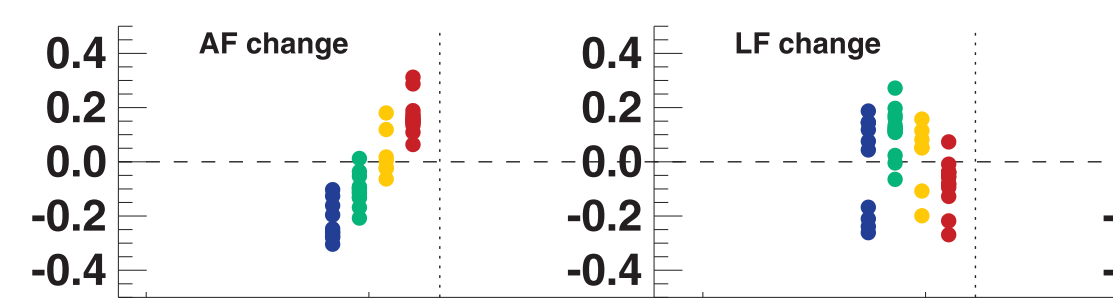

1990s 2006-2100
1.0

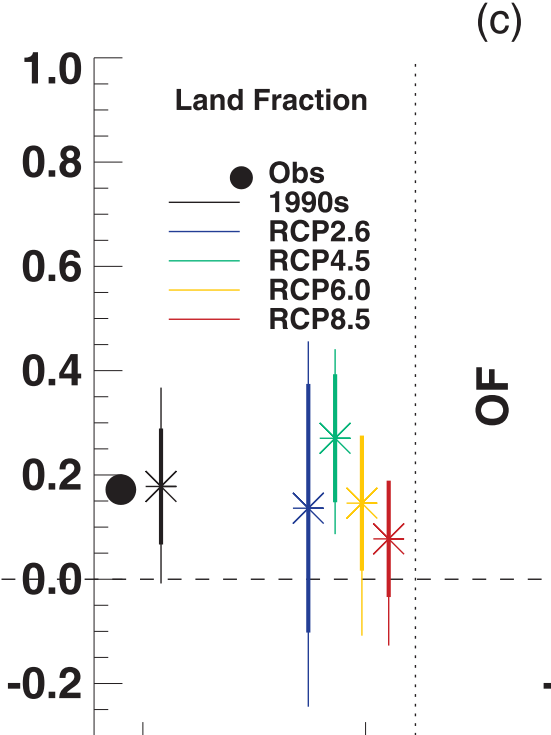

(c)

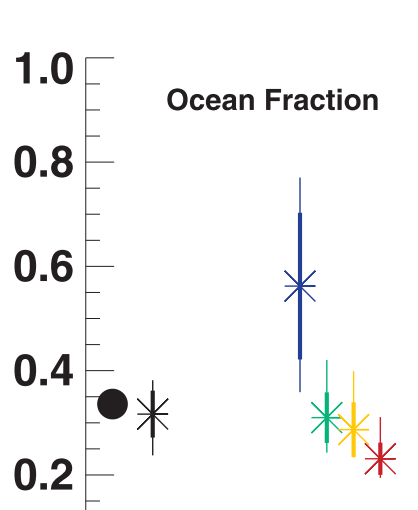

FIG. 7. (top) Changes in (a) airborne, (b) land, and (c) ocean fraction of compatible fossil-fuel emissions. Multimodel mean, \pm standard deviation, and range shown by stars and thick and thin vertical lines, respectively, for 1990s (black) and four RCPs (colored). Observational estimate for 1990s is shown as black dots. RCP values are calculated as cumulative over the twenty-first century (defined for RCPs as 2006-2100). (bottom) The changes in each uptake fraction shown for individual models (each dot is a separate model).

period. The airborne fraction can be calculated relative to fossil-fuel emissions (as per Keeling et al. 1995) or more commonly relative to total anthropogenic (fossil + land use) emissions (e.g., Denman et al. 2007; Le Quéré et al. 2009). The observed AF has been relatively constant apart from interannual variability for several decades since direct $\mathrm{CO}_{2}$ observations began in the late 1950s (Keeling et al. 1995; Denman et al. 2007). Recent studies have claimed a small but measurable upward trend is now detectable in the observations (Canadell et al. 2007; Le Quéré et al. 2009), although uncertainty in land-use emissions makes this detection difficult (Knorr 2009). AF is not simply a constant property of the climate-carbon cycle system but depends strongly on the emissions pathway. Faster increase in emissions implies higher airborne fraction since the land and ocean carbon sinks are unable to keep up with the rate of emissions. Consequently, any deviation from the historical near-exponential increase in anthropogenic emissions may be expected to lead to significant changes in AF (Raupach et al. 2008).
Because of the difficulties of diagnosing land-use emissions consistently from CMIP5 models, we present here explicitly the fossil-fuel $\mathrm{AF} f_{A}$ [see Eq. (4)] calculated from prescribed changes in atmospheric $\mathrm{CO}_{2}$ and the compatible fossil-fuel emissions from the ES-GCMs presented in section $3 \mathrm{c}$. To prevent large interannual variability affecting our results (especially the case for scenarios where emissions become very small or even zero or negative), we calculate a cumulative $f_{A}$ over the period 1990-99 and also over 2006-2100 for the four RCPs.

The 1990s value can be compared with observational estimates, which we calculate as 0.49 (average $\mathrm{CO}_{2}$ increase of $3.15 \mathrm{PgC} \mathrm{yr}^{-1}$ and fossil-fuel emissions of

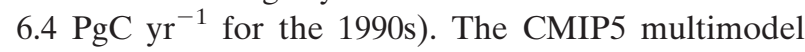
mean is $0.52 \pm 0.07$ (range of $0.45-0.65$ ), with 9 of 13 models falling between 0.45 and 0.55 (Fig. 7).

Figure 7 shows the change of $f_{A}$ from the 1990s to the twenty-first century from the CMIP5 models for the four RCPs. The figure also shows land and oceanic uptake fractions of fossil fuel $f_{L}$ and $f_{O}$, which are defined 
similarly as the fractional uptake of the compatible emissions by land or ocean [Eq. (4)].

A notable feature of the simulations is that during the course of each simulation $f_{A}$ can vary markedly over the twenty-first century relative to the 1990s. It evolves very differently for different scenarios and even simulated by the same model may increase or decrease, depending on the scenario. From a present-day average value of 0.52 (cf. 0.49 estimated from observations), the models simulate values ranging from 0.18 to 0.82 over the twentyfirst century. As may be expected from the theoretical grounds discussed above, in the CMIP5 simulations the lower RCP pathways give rise to lower AF and higher $\mathrm{CO}_{2}$ concentrations lead to higher AF. All models simulate a decrease in AF for RCP2.6 and all but one simulate a decrease for RCP4.5. All models simulate an increase for RCP8.5. RCP6.0 has on average very small change with four models simulating an increase in AF and three simulating a decrease. Model mean values for the twenty-first-century airborne fraction for each scenario are as follows: 0.30 for RCP2.6; 0.42 for RCP4.5; 0.57 for RCP6.0; and 0.69 for RCP8.5. The emissions pathway is the leading order cause of changes in AF having a greater effect than the climate effect on the carbon cycle. Although there is much model spread in magnitude and change of AF, every model agrees on the order of $f_{A}$ across scenarios: RCP8.5 $>$ RCP6.0 $>$ $\mathrm{RCP} 4.5>\mathrm{RCP} 2.6$.

Figure $7 \mathrm{~b}$ shows future changes in the land fraction of emissions. There is much model spread in this quantity, in part related to the treatment of land-use in these models and in part to how vegetation and soil carbon dynamics are represented in them. Out of 13 models, 11 simulate an increase in $f_{L}$ for RCP 4.5 by on average 0.11 because of a decrease in both crop fraction and pasture fraction and the associated increase in forest area. The RCP6.0 scenario includes a decrease in pasture area but an increase in crop fraction, which combine to give very little change in the average land uptake fraction with five models showing an increase and two showing a decrease. RCP8.5 has large-scale future increases in crop and pasture leading to suppression of the land sink and a small decrease in $f_{L}$. A total of 12 out of 13 models agree on a decrease in $f_{L}$ for RCP8.5. This demonstrates the importance of land use for the future terrestrial carbon store and that this may be of comparable importance to the response of terrestrial carbon to climate or increased $\mathrm{CO}_{2}$. RCP2.6 has generally the smallest increase in land carbon (Fig. 3a) and much lower compatible emissions than the other scenarios. This combination of smaller numbers in both the numerator and denominator in the land-fraction ratio leads to a much bigger model spread for this scenario with some models showing a large increase and some a large decrease in $f_{L}$.

Figure $7 \mathrm{c}$ shows twenty-first-century ocean carbon uptake fraction $f_{O}$. For two scenarios, RCP6.0 and RCP8.5, there is a common signal across models of reduction in the ocean uptake fraction and small spread across models (consistent with ocean fluxes discussed in section $3 b$ ). RCP4.5 has a mixed signal with four models simulating an increase in ocean uptake fraction and nine simulating a decrease. RCP2.6 is a clear outlier in $f_{O}$ behavior, showing a large increase for all models. Significant model spread can be seen in the RCP2.6 ocean fraction and is explained in this case, not by model spread in oceanic uptake, but by model spread in the compatible emissions. Remember that $f_{O}$ is defined as the ratio of changes in ocean carbon to compatible emissions, which themselves are sensitive to land uptake changes. Hence, in this analysis, where compatible emissions are diagnosed from simulations with prescribed atmospheric $\mathrm{CO}_{2}$ pathways, uncertainty in land uptake manifests itself as uncertainty in the fraction of emissions taken up by the ocean even though it does not directly affect the oceanic uptake amount.

\section{Conclusions}

The global carbon cycle, as well as its response to changing climate and $\mathrm{CO}_{2}$ concentrations, determines future anthropogenic emissions permitted to follow any given $\mathrm{CO}_{2}$ pathway and is therefore of relevance to both the scientific and policy communities. The CMIP5 modeling activity provides a coordinated protocol for climate modeling centers to perform concentrationdriven simulations for the four representative concentration pathways with state-of-the-art Earth system GCMs in order to diagnose the compatible emissions. Here, we present results from 15 such models although each model may only currently have provided a subset of the required data and scenarios. Compatible fossil-fuel emissions are calculated for 13 models that represent anthropogenic land-use change in their simulations.

The concentration-driven framework for model simulations reduces spread in climate projections by preventing feedback from the carbon cycle onto atmospheric $\mathrm{CO}_{2}$ and hence climate, but it produces spread in emissions (e.g., see Fig. 2 of Hibbard et al. 2007). The compatible emissions thus derived include uncertainty from all processes (climate, climate-carbon, and carbon concentration) but without these processes operating as fully interactive feedbacks. The emissions-driven framework for model simulations allows full end-to-end uncertainty in $\mathrm{CO}_{2}$ and climate with fully interactive 
feedbacks (Friedlingstein et al. 2012, manuscript submitted to J. Climate).

We have shown that there is significant model spread in the diagnosed compatible emissions, dominated by projections of land carbon changes, due in part to the diverse response of land carbon cycle models to changes in $\mathrm{CO}_{2}$ and climate and widely different treatments of land-use change. We recommend that particular effort is required to better evaluate and improve terrestrial carbon cycle stocks in ES-GCMs. Anav et al. (2013) show a very wide range of vegetation and soil carbon stores simulated and, although there is not a one-to-one relation between present stocks and future changes, it is clearly a priority for ES-GCMs to better represent the magnitude of carbon amounts before we can have confidence in projections of future changes.

We find that land carbon storage may increase or decrease in future dependent on scenario and the treatment of future land-use change, although most models simulate an increase for most scenarios. The spread in land carbon uptake among models is as high as across the RCP scenarios. Models largely agree that ocean carbon storage will increase under all scenarios, with higher atmospheric $\mathrm{CO}_{2}$ driving greater ocean carbon uptake. Projections of ocean carbon changes show much greater agreement than projections of land carbon changes. Overall, uncertainty in concentration scenario is the major cause of uncertainty in emissions (and airborne fraction) and not uncertainty in climate-carbon cycle processes.

CMIP5 simulated compatible fossil-fuel emissions for the historical period $(303 \pm 61 \mathrm{PgC})$ agree closely with historical estimates ( $313 \mathrm{PgC})$, as do CMIP5 model mean uptake amounts for the land and ocean individually. CMIP5 Earth system GCMs also show close agreement with the low RCPs (RCP2.6 and RCP4.5). For RCP6.0 and especially RCP8.5 they simulate systematically lower carbon uptake and therefore lower compatible emissions than the RCP scenarios generated by the MAGICC6 model calibrated to CMIP3 climate and $\mathrm{C}^{4} \mathrm{MIP}$ carbon cycle GCMs.

Compatible emissions for the four RCPs (defined for the period 2006-2100) range from 332 to $1734 \mathrm{PgC}$ for RCP2.6-RCP8.5. For the period 2000-50, model-mean cumulative emissions range from $337 \mathrm{PgC}$ for RCP2.6 to $602 \mathrm{PgC}$ for RCP8.5, with RCP4.5 and RCP6.0 having very similar totals over this period of 523 and $453 \mathrm{PgC}$, respectively. RCP6.0 exceeds RCP4.5 later in the century. For RCP2.6 models simulate a requirement on average for $50 \%$ emissions reductions by 2050 relative to 1990 levels but with very large model spread in this measure from $14 \%$ to $96 \%$. The Integrated Model to Assess the Global Environment (IMAGE), which generated the RCP2.6 scenario, projected the need for globally negative emissions from 2070 to 2100 in order to achieve the peak-and-decline $\mathrm{CO}_{2}$ pathway. We find that 6 out of 10 complex Earth system models also simulate a need for negative emissions, while 4 do not.

Future airborne fraction, averaged over the twentyfirst century, is found to be strongly dependent on the anthropogenic emissions scenario as are the fractions of emissions taken up by land and ocean. All models agree that the higher the atmospheric $\mathrm{CO}_{2}$ scenario, the higher the airborne fraction and the lower the ocean uptake fraction. The land uptake fraction is sensitive to both the $\mathrm{CO}_{2}$ and climate scenario but also strongly depends on the land-use change assumed, which is not necessarily related to global $\mathrm{CO}_{2}$ levels. Out of 13 models, 11 agree that the mid-low $\mathrm{CO}_{2}$ scenario, $\mathrm{RCP} 4.5$, has the highest land-uptake fraction during the twenty-first century because of decreases in areas of agriculture and increases in forest extent. Increases in land-use areas in RCP2.6 and RCP8.5 lead to reduced land-uptake fractions in these scenarios.

Acknowledgments. MOHC authors were supported by the Joint DECC/Defra Met Office Hadley Centre Climate Programme (GA01101), and work to perform HadGEM2ES and MPI-ESM CMIP5 simulations was supported by the EU-FP7 COMBINE project (Grant 226520). JS was supported by the EU-FP7 CARBOCHANGE project (Grant 284679). We acknowledge the World Climate Research Programme's Working Group on Coupled Modelling, which is responsible for CMIP, and we thank the climate modeling groups (listed in Table 1 of this paper) for producing and making available their model output. For CMIP, the U.S. Department of Energy's Program for Climate Model Diagnosis and Intercomparison provides coordinating support and led development of software infrastructure in partnership with the Global Organization for Earth System Science Portals. JT and CR were supported by the Research Council of Norway through the EarthClim (207711/E10) project.

\section{APPENDIX}

\section{Diagnosing Emissions from Changes in Carbon Stores}

Figure A1 shows schematically how the carbon pools that are represented in these models respond to fossilfuel emissions and emissions from land-use/land-cover change. We regard the atmosphere-land-ocean system as a closed system here, as none of these models represent the longer-term fluxes due to rock weathering, volcanism, etc. Thus, without perturbation, the total system 
Initial pulse

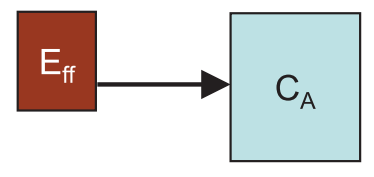

Fossil emissions

\section{LU emissions}

Fossil AND LU emissions

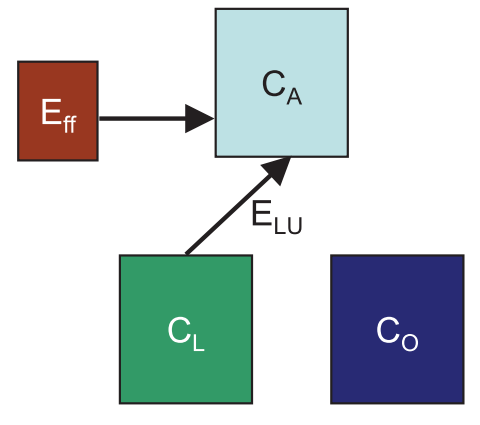

$$
\begin{aligned}
& \Delta C_{A}=E_{f f}+E_{L U} \\
& \Delta C_{L}=-E_{L U} \\
& \Delta C_{O}=0 \\
& \Delta C(A+L+O)=E_{f f}
\end{aligned}
$$

\section{After redistribution}

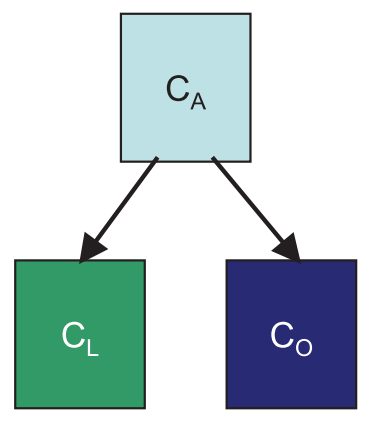

$$
\Delta \mathrm{C}(\mathrm{A}+\mathrm{L}+\mathrm{O})=\mathrm{E}_{\mathrm{ff}}
$$

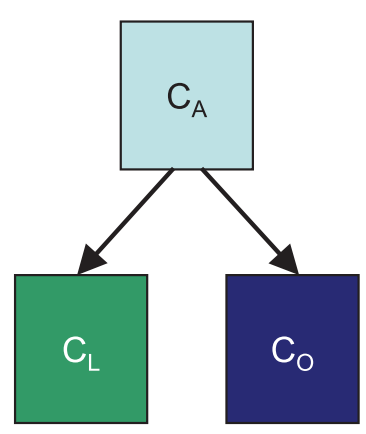

$$
\Delta C(A+L+O)=0
$$

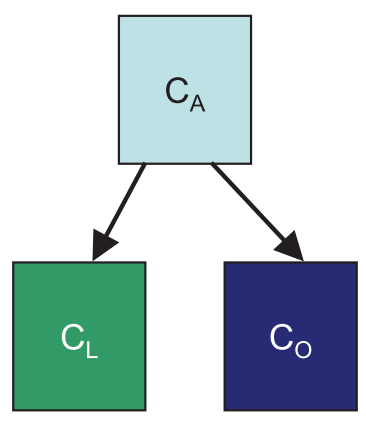

$\Delta \mathrm{C}(\mathrm{A}+\mathrm{L}+\mathrm{O})=\mathrm{E}_{\mathrm{ff}}$

FIG. A1. Schematic demonstrating the difference between fossil and land-use $\mathrm{CO}_{2}$ emissions in a closed atmosphereland-ocean system. (top) Fossil-fuel emissions represent an addition of new carbon to the system, initially to the atmosphere, but after redistribution between the component reservoirs the total perturbed amount is conserved. (middle) Land-use emissions represent an initial movement of carbon from the land to atmosphere with zero net change in the system. Even after redistribution, between the components the net change remains zero. When both fossil and land-use emissions are present, they combine such that the total carbon in the system only changes by the fossil-fuel input, with land-use emissions again having no net impact on the system total. 
carbon, $C_{\mathrm{Tot}}=C_{A}+C_{L}+C_{O}$, remains constant in time: $\Delta C_{\mathrm{Tot}}=0$. By using ocean flux to diagnose changes in ocean storage, sedimentation, which is included in some models can be seen as an internal partitioning within a generic "ocean carbon" pool in this analysis.

The top panel of Fig. A1 shows the evolution of the system in response to fossil-fuel emissions: when fossil fuel is added, the total system carbon increases by $E_{F}$ : all of which is initially in the atmosphere. After some finite time the system has responded (not necessarily reaching equilibrium) by repartitioning the added carbon among its reservoirs, but the total system carbon has not changed and, relative to the unperturbed state, $\Delta C_{\text {Tot }}=$ $E_{F}$. The same is true for a transient, continued (but time varying) emission. At any point in time, the rate of change of total carbon is given by the emission rate $E_{\mathrm{ff}}$ and the total change in system carbon by the cumulative emission,

$$
\begin{aligned}
& \frac{d C_{\mathrm{Tot}}}{d t}=E_{\mathrm{ff}} \\
& \Delta C_{\mathrm{Tot}}=\int_{0}^{t} E_{\mathrm{ff}} d t .
\end{aligned}
$$

Conversely, the middle panel of Fig. A1 shows the system response to a land-use change. In this case, some externally forced disturbance event acts to repartition some of the land carbon initially into the atmosphere, such that $\Delta C_{L}=-E_{\mathrm{LUC}}$ and $\Delta C_{A}=E_{\mathrm{LUC}}$. Initially, $\Delta C_{O}$ is zero, and so the total system carbon is unchanged, $\Delta C_{\text {Tot }}=0$. After some time, the system may respond to move carbon between the reservoirs (e.g., $\Delta C_{O}$ may change), but overall $\Delta C_{\mathrm{Tot}}=0$. In other words, land-use change may represent a strong perturbation to the land carbon and ultimately to all the three reservoirs individually, but as a closed system it does not change the total amount of carbon. Note that in each case the fossil or land-use emissions may be positive or negative: removal (such as through forest regrowth or deliberate carbon dioxide removal) as well as emission is treated in conceptually the same way.

The bottom panel of Fig. A1 shows the response to both fossil and land-use emissions together. Although the specific effects of the emissions (and indeed any changes in climate) on the individual carbon reservoirs may not be the simple sum of the two sources of emissions, the net effect on the system total carbon is simply that due to fossil emissions: $\Delta C_{\mathrm{Tot}}=E_{F}$. The land-use emissions have had no net effect on the total carbon in the system.

This schematic represents how the CMIP5 ES-GCMs behave in "emissions driven" simulations and how the real world behaves on time scales where other long-term sources/sinks of carbon can be neglected (typically up to a few centuries). However, for the "concentration driven" simulations analyzed here, the system is not balancing and conserving carbon in this way. Emissions do not exist as an input to the system, but rather the evolution of $C_{A}$ is forced to follow a predefined pathway used as an input to the models. Here, $C_{L}$ and $C_{O}$ respond to this concentration and also to any changes in climate and in response to prescribed land-use disturbance but do not affect $C_{A}$ itself. In this case the system total carbon evolves in time: $\Delta C_{\text {Tot }} \neq 0$. By analogy to the schematic in Fig. A1a, we can see that the time evolution of $\Delta C_{\text {Tot }}$ is the fossil-fuel emission $E_{F}$ and not the total $E_{F}+E_{\mathrm{LUC}}$. In other words, in order to recreate the $\mathrm{CO}_{2}$ concentration pathway in an emissions-driven setup, one would prescribe this diagnosed emission as the fossil-fuel input to the system. In these simulations, therefore, the effect of land use will be to perturb the land carbon cycle and to affect how carbon is partitioned between the three reservoirs.

\section{REFERENCES}

Anav, A., and Coauthors, 2013: Evaluating the land and ocean components of the global carbon cycle in the CMIP5 Earth system models. J. Climate, in press.

Arora, V. K., and G. J. Boer, 2010: Uncertainties in the 20th century carbon budget associated with land use change. Global Change Biol., 16, 3327-3348.

— satisfy future representative concentration pathways of greenhouse gases. Geophys. Res. Lett., 38, L05805, doi:10.1029/ 2010GL046270.

— , and Coauthors, 2013: Carbon-concentration and carbonclimate feedbacks in CMIP5 Earth system models. J. Climate, in press.

Booth, B. B. B., and Coauthors, 2012: High sensitivity of future global warming to land carbon cycle processes. Envon. Res. Lett., 7, 024002, doi:10.1088/1748-9326/7/2/024002.

Brovkin, V., and Coauthors, 2013: Effect of anthropogenic landuse and land-cover changes on climate and land carbon storage in CMIP5 projections for the twenty-first century. J. Climate, in press.

Canadell, J. G., and Coauthors, 2007: Contributions to accelerating atmospheric $\mathrm{CO}_{2}$ growth from economic activity, carbon intensity, and efficiency of natural sinks. Proc. Nat. Acad. Sci. USA, 104, 18 866-18 870.

Denman, K. L., and Coauthors, 2007: Couplings between changes in the climate system and biogeochemistry. Climate Change 2007: The Physical Science Basis, S. Solomon et al., Eds., Cambridge University Press, 499-587.

Friedlingstein, P., and Coauthors, 2006: Climate-carbon cycle feedback analysis: Results from the $\mathrm{C}^{4} \mathrm{MIP}$ model intercomparison. J. Climate, 19, 3337-3353.

Gullison, R. E., and Coauthors, 2007: Tropical forests and climate policy. Science, 316, 985-986, doi:10.1126/science.1136163.

Hibbard, K. A., G. A. Meehl, P. Cox, and P. Friedlingstein, 2007: A strategy for climate change stabilization experiments. Eos, Trans. Amer. Geophys. Union, 88, 217, doi:10.1029/2007EO200002. 
Houghton, R. A., cited 2008: Carbon flux to the atmosphere from land-use changes: 1850-2005. Trends: A compendium of data on global change, U.S. Department of Energy Oak Ridge National Laboratory Carbon Dioxide Information Analysis Center. [Available online at http://cdiac.ornl.gov/trends/ landuse/houghton/houghton.html.]

Hurtt, G., and Coauthors, 2011: Harmonization of land-use scenarios for the period 1500-2100: 600 years of global gridded annual land-use transitions, wood harvest, and resulting secondary lands. Climatic Change, 109, 117-161, doi:10.1007/ s10584-011-0153-2.

Johns, T. C., and Coauthors, 2011: Climate change under aggressive mitigation: The ENSEMBLES multi-model experiment. Climate Dyn., 37, 1975-2003, doi:10.1007/s00382-011-1005-5.

Jones, C. D., P. M. Cox, and C. Huntingford, 2006: Climate-carbon cycle feedbacks under stabilization: Uncertainty and observational constraints. Tellus, 58B, 603-613.

Keeling, C. D., T. Whorf, M. Whalen, and J. V. der Plicht, 1995: Interannual extremes in the rate of rise of atmospheric carbon dioxide since 1980. Nature, 375, 666-670.

Knorr, W., 2009: Is the airborne fraction of anthropogenic $\mathrm{CO}_{2}$ emissions increasing? Geophys. Res. Lett., 36, L21710, doi:10.1029/2009GL040613.

Le Quéré, C., and Coauthors, 2009: Trends in the sources and sinks of carbon dioxide. Nat. Geosci., 2, 831-836, doi:10.1038/ngeo689.

Matthews, H. D., 2006: Emissions targets for $\mathrm{CO}_{2}$ stabilization as modified by carbon cycle feedbacks. Tellus, 58B, 591-602.

Meinshausen, M., and Coauthors, 2011: The RCP greenhouse gas concentrations and their extension from 1765 to 2300 . Climatic Change, 109, 213-241, doi:10.1007/s10584-011-0156-z.
Moss, R., and Coauthors, 2010: The next generation of scenarios for climate change research and assessment. Nature, 463, 747-756.

Plattner, G.-K., and Coauthors, 2008: Long-term climate commitments projected with climate-carbon cycle models. J. Climate, 21, 2721-2751.

Prentice, I. C., and Coauthors, 2001: The carbon cycle and atmospheric carbon dioxide. Climate Change 2001: The Scientific Basis, J. T. Houghton et al., Eds., Cambridge University Press, 183-238.

Raupach, M. R., J. G. Canadell, and C. Le Quéré, 2008: Anthropogenic and biophysical contributions to increasing atmospheric $\mathrm{CO}_{2}$ growth rate and airborne fraction. Biogeosciences, 5, 1601-1613.

Sabine, C. L., and R. A. Feely, 2007: The oceanic sink for carbon dioxide. Greenhouse Gas Sinks, D. S. Reay et al., Eds., CABI, 31-49.

Taylor, K. E., R. J. Stouffer, and G. A. Meehl, 2012: An overview of CMIP5 and the experiment design. Bull. Amer. Meteor. Soc., 93, 485-498.

Todd-Brown, K. E. O., J. T. Randerson, W. M. Post, F. M. Hoffman, C. Tarnocai, E. A. G. Schuur, and S. D. Allison, 2013: Causes of variation in soil carbon simulations from CMIP5 Earth system models and comparison with observations. Biogeosciences, 10, 1717-1736, doi:10.5194/bg-10-1717-2013.

Trudinger, C. M., I. G. Enting, P. J. Rayner, and R. J. Francey, 2002: Kalman filter analysis of ice core data 2. Double deconvolution of $\mathrm{CO}_{2}$ and $\delta^{13} \mathrm{C}$ measurements. J. Geophys. Res., 107, 4423, doi:10.1029/2001JD001112.

van Vuuren, D. P., and Coauthors, 2011: The representative concentration pathways: An overview. Climatic Change, 109, 5-31, doi:10.1007/s10584-011-0148-z. 